\title{
Formoterol in patients with chronic obstructive pulmonary disease: a randomized, controlled, 3-month trial
}

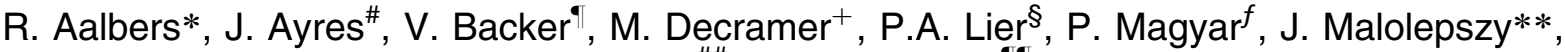 \\ R. Ruffin ${ }^{\# \#}$, G.W. Sybrecht ${ }^{\text {甲 }}$
}

Formoterol in patients with chronic obstructive pulmonary disease: a randomized, controlled, 3-month trial. R. Aalbers, J. Ayres, V. Backer, M. Decramer, P.A. Lier, P. Magyar, J. Malolepszy, R. Ruffin, G.W. Sybrecht. (C) ERS Journals Ltd 2002.

ABSTRACT: The aim of this study was to investigate formoterol, an inhaled longacting $\beta_{2}$-agonist, in patients with chronic obstructive pulmonary disease (COPD).

Six-hundred and ninety-two COPD patients, mean baseline forced expiratory volume in one second (FEV1) 54\%, FEV1/forced vital capacity $75 \%$ of predicted, reversibility $6.4 \%$ pred, were treated with formoterol $(4.5,9$ or $18 \mu \mathrm{g} \mathrm{b.i.d.)}$ or placebo via Turbuhaler $\AA$ for 12 weeks. Symptoms were recorded daily. Spirometry and the incremental shuttle walking test (SWT) were performed at clinic visits.

Compared with placebo, $18 \mu \mathrm{g}$ b.i.d. formoterol reduced the mean total symptom score by $13 \%$ and increased the percentage of nights without awakenings by $15 \%$. Formoterol $(9$ and $18 \mu \mathrm{g}$ b.i.d. $)$ significantly reduced symptom scores for breathlessness $(-7 \%$ and $-9 \%$, respectively) and chest tightness $(-11 \%$ and $-8 \%$, respectively), reduced the need for rescue medication $(-25 \%$ and $-18 \%$, respectively), and increased symptomfree days $(71 \%$ and $86 \%$, respectively). FEV1 improved significantly after all three doses of formoterol (versus placebo). No differences were found between groups in SWT walking distance. No unexpected adverse events were seen.

In conclusion, 9 and $18 \mu \mathrm{g}$ b.i.d. formoterol reduced symptoms and increased the number of symptom-free days in a dose-dependent manner in chronic obstructive pulmonary disease patients. Formoterol improved lung function at a dose of $4.5 \mu \mathrm{g}$ b.i.d. and higher.

Eur Respir J 2002; 19: 936-943.

\begin{abstract}
* Martini Hospital, Groningen, The Netherlands. " Birmingham Heartlands Hospital, Birmingham, UK. "Bispebjerg Hospital, Copenhagen, Denmark. ${ }^{+}$UZ Gasthuisberg, Leuven, Belgium. ${ }^{\S}$ Humana Medical Centre, Sandvika, Norway. ${ }^{f}$ Semmelweis University, Budapest, Hungary. **Dept of Internal Medicine and Allergology, Wroclaw Medical Hospital, Wroclaw, Poland. \#\# The Queen Elizabeth Hospital, Woodville South, Australia. "Medical Hospital and Health Centre, Homburg, Germany.
\end{abstract}

Correspondence: G.W. Sybrecht, Medizinische Universitätskliniken, Inner Medizin V, D-66241 Homburg, Germany. Fax: 4968411623602

E-mail: pngsyb@uniklinik-saarland.de

Keywords: Bronchodilation, chronic obstructive pulmonary disease, formoterol

Received: April 272001

Accepted after revision January 92002

This study was supported by AstraZeneca
According to the definition of the European Respiratory Society (ERS) [1], chronic obstructive pulmonary disease (COPD) is "a disorder characterized by reduced maximum expiratory flow and slow forced emptying of the lungs; features which do not change markedly over several months. Most of the airflow limitation is slowly progressive and irreversible". COPD is one of the major causes of morbidity and mortality in the world, and its prevalence is increasing [2].

The role of $\beta_{2}$-agonists as bronchodilators is well defined in asthma, and they are also recommended by international guidelines $[1,3,4]$ for symptomatic relief in COPD. Studies have shown that bronchodilator treatment can reduce disease symptoms and improve exercise capacity and lung function in patients with COPD [5, 6]. However, results have varied considerably between studies and there is no correlation between changes in forced expiratory volume in one second (FEV1) and symptoms. The element of reversible bronchoconstriction in COPD can be expected to respond to $\beta_{2}$-agonists, but since the disease is characterized by a low FEV 1 that hardly responds to bronchodilators, other measures also need to be considered. An improvement in exercise capacity, and a reduction of symptoms and dyspnoea during exertion in daily activities can have a major impact on the patient's quality of life and ability to function and may form an aim of therapy.

Formoterol fumarate (formoterol), is a $\beta_{2}$-agonist with a rapid onset and long duration of action in asthma [7]. Maintenance treatment with formoterol should be investigated in patients with COPD.

\section{Materials and methods}

\section{Patients}

Males and females aged 50-80 yrs were eligible for inclusion in the study if they were current or former smokers, had a smoking history of at least 10 packyrs, and had a clinical diagnosis of COPD. At randomization, their prebronchodilator FEV1 had to be $>0.7 \mathrm{~L}$ and $40-70 \%$ of predicted, the FEV1/forced vital capacity (FVC) ratio $<89 \%$ pred normal for 
females and $<88 \%$ for males, and the total symptom score (see later) had to be $\geqslant 2$ on at least 7 days of the run-in period.

Patients with a history of asthma or seasonal allergic rhinitis before the age of 40 yrs, any current respiratory tract disorder other than COPD, significant or unstable heart disease, or any other clinically significant gastrointestinal, hepatic, renal or endocrine disease were excluded. Patients requiring domiciliary oxygen and those using $\beta$-blockers were not allowed to participate, neither were patients who had suffered an exacerbation of COPD requiring medical intervention during the run-in period or within 30 days prior to enrolment.

\section{Study design}

This was a randomized, double-blind, parallelgroup study involving 86 centres in nine countries (Australia, Belgium, Denmark, Germany, Hungary, The Netherlands, Norway, Poland, and UK). After a 2-week run-in period, patients were randomized to treatment for 12 weeks with $4.5 \mu \mathrm{g}, 9 \mu \mathrm{g}$, or $18 \mu \mathrm{g}$ b.i.d. formoterol (Oxis $\AA$ T Turbuhaler $\mathbb{R}$, AstraZeneca, Lund, Sweden) or placebo. These doses were given as "delivered dose" and corresponded to 6, 12 and $24 \mu \mathrm{g}$ "metered dose" respectively. Patients visited the clinic at enrolment (Visit 1), randomization (Visit 2), and after 6 and 12 weeks of treatment (Visits 3 and 4, respectively).

Terbutaline sulphate $\left(0.5 \mathrm{mg} \cdot \mathrm{dose}^{-1}\right.$, Bricanyl $\mathbb{R}$

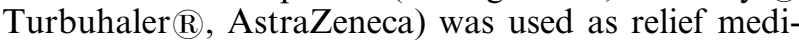
cation during run-in and throughout the study; no other bronchodilator therapy was used. Inhaled and oral glucocorticosteroids were allowed throughout the study at a constant dose (highest oral doses: $10 \mathrm{mg}$ prednisolone $\cdot$ day $^{-1}, 8 \mathrm{mg}$ methylprednisolone $\cdot$ day $^{-1}$ or $1 \mathrm{mg}$ betamethasone $\cdot \mathrm{day}^{-1}$ ). Patients were not allowed to use inhaled and oral $\beta_{2}$-agonists (apart from relief medication), inhaled anticholinergics, xanthine derivatives, leukotriene antagonists, medication containing ephedrine, and parenteral glucocorticosteroids.

\section{Assignment and blinding}

Patients were randomized to the four treatments in balanced blocks using a computer-generated schedule after completing the run-in period. Individually sealed treatment codes indicating the allocated treatment for each patient were available at each clinic for emergency situations. All inhalers used in the study were of identical appearance, and active and placebo inhalers were indistinguishable in taste.

\section{Assessments}

Patients used diary cards to record symptoms, sleep disturbance and intake of relief medication on a daily basis. Symptoms were graded using a modification of the scale described in the National Mucolytic Study [8]. Individual daytime symptoms (breathlessness, cough and chest tightness) and night-time sleep disturbance were each given a score of $0-4$, where 0 denoted no symptoms and 4 indicated the greatest severity. Since geometric means were used for statistical analysis, one unit was added to the sum score in each case, resulting in a scale of 1-17 for the calculated total symptom score.

Spirometry variables (FVC, FEV1, and forced midexpiratory flow (FEF25-75\%)) were measured before the start of the shuttle walking test (SWT) at each clinic visit. At least three technically satisfactory FVC tests were required and $\mathrm{FEV} 1$ was taken from the FVC test. The largest FVC and FEV1 values were recorded, even if not taken from the same curve. FEV1/FVC was calculated by dividing the largest values of both FEV1 and FVC. FEF25-75\% values were derived from the FVC curve that gave the largest sum of FVC plus FEV1. Predicted normal values for FEV1 and FEV1/FVC were calculated according to the European Respiratory Society guidelines [9]. Reversibility was tested at visit 1 by measuring FEV1 before and $15 \mathrm{~min}$ after inhalation of $1 \mathrm{mg}$ terbutaline sulphate (Bricanyl $\mathbb{R}$ Turbuhaler $\left(\mathrm{R} ; 0.5 \mathrm{mg} \cdot \mathrm{dose}^{-1}\right.$ ).

An incremental SWT [10] was performed at each clinic visit, the first visit served for training purposes only. Briefly, patients were instructed to walk back and forth in 10-m "shuttles" at a gradually increasing pace until they were unable to complete the distance in the time allowed. No additional encouraging was given during the SWT. Oxygen saturation was monitored via a pulse oximeter set to alarm if saturation fell below $80 \%$, in which case the test was stopped and the patient withdrawn from the study. Before and after the test, dyspnoea was graded by the patient using the 10 -grade Borg scale $(0=$ none and $10=$ severe $)$ [11]. Pulse and blood pressure were also recorded.

Symptoms of COPD were additionally assessed at clinic visits using the Baseline Dyspnoea Index (BDI) and the Transitional Dyspnoea Index (TDI) covering functional capacity, magnitude of task and magnitude of effort due to breathlessness [12]. The BDI questionnaire was completed at randomization and the TDI questionnaire was completed at other visits, prior to pulmonary function tests and SWT. The three categories were each graded from 0 (severe) to 4 (unimpaired) in the BDI; at follow-up, the TDI questionnaire was used to assess the change in each category, graded from -3 (major deterioration) to +3 (major improvement).

\section{Safety}

To obtain information about adverse events the patients were asked a standardized question at each visit, whether they had experienced any health problems since the previous visit or not. In addition, the following safety measurements were performed at enrolment and the final visit: Electrocardiogram (standard 12-lead), pulse, blood pressure, general physical examination and laboratory tests, including haematology, clinical chemistry and urinalysis. 


\section{Statistical evaluation}

The sample-size calculation for the total symptom score was based on results from the National Mucolytic Study [8] in which calculations were based on the derived global assessment. A difference of 0.92 in the global assessment was seen between treatments in the mucolytic study with a corresponding SD of 3.0. It was assumed that the total symptom score, as defined earlier, had a similar statistical performance. Thus, if the SD was 3.0, it was estimated that 120 evaluable patients per arm were required: with this number of patients completing per group, a difference of 1.1 in overall symptom scores would have been detectable $(80 \%$ power, significance level 5\%). An intention-to-treat approach was used to analyse all data, except for patients withdrawn within 14 days of randomization due to noneligibility.

The main analysis model was an analysis of variance, with the baseline value as covariate and the end of treatment value as the dependent variable. Treatment, country and their interaction were factors, with treatment contrasts weighted according to country size. For the diary card variables, baseline values were calculated as averages over the last 10 days of the run-in period, and end of treatment measurements as averages over the last 60 days of treatment. For the variables recorded at the clinic, the measurements made at the randomization visit were regarded as baseline values. A multiplicative model was used for spirometry values and symptom scores (total and individual), and additive models were used for the other variables.

\section{Results}

\section{Patients}

Of the 918 patients enrolled, 692 were randomized to treatment and 576 completed the study. Three patients were withdrawn from the study within 14 days of randomization, and two others were randomized but never received any medication; the efficacy analysis was therefore performed on 687 patients. The groups were similar in demographic and baseline characteristics (table 1). Average walking distance at baseline was about $400 \mathrm{~m}$ (range 60$1020 \mathrm{~m}$ ) for all groups. Spirometry variables were similar for all groups. The patient population were regarded as having moderate to severe COPD, as is evident from the mean $\mathrm{FEV} 1$ of $54 \%$ pred (range $30-73 \%$ ), mean FEV1/FVC ratio of $75 \%$ pred and a mean reversibility of $6 \%$ pred (table 1 ). In $9 \%$ of the patients, equally distributed over the four treatment groups, the FEV1/FVC ratio was above the value required in the protocol $(<88 \%$ or $89 \%$ pred) due to miscalculations, like using the absolute ratio instead of the ratio as $\%$ pred. Additionally, $23 \%$ of patients could be regarded as "reversible", showing an increase of $>10 \%$ pred at enrolment. Excluding these groups of patients had no major influence on the study outcomes (data not shown in detail).

\section{Symptom scores}

During run-in, the average total symptom score was 5.63 (range 1.0-14.2). A significant (13\%) reduction

Table 1. - Patient characteristics at baseline

\begin{tabular}{|c|c|c|c|c|c|}
\hline Characteristic & $\begin{array}{l}\text { Formoterol } \\
4.5 \mu \mathrm{g}\end{array}$ & $\begin{array}{l}\text { Formoterol } \\
\quad 9 \mu \mathrm{g}\end{array}$ & $\begin{array}{l}\text { Formoterol } \\
\qquad 18 \mu \mathrm{g}\end{array}$ & Placebo & All \\
\hline $\begin{array}{l}\text { Patients in efficacy } \\
\text { analysis } \mathrm{n}(\mathrm{M}: \mathrm{F})\end{array}$ & $171(112: 59)$ & $166(119: 47)$ & $177(123: 54)$ & $173(113: 60)$ & $687(467: 220)$ \\
\hline $\begin{array}{l}\text { Patients who completed } \\
\text { study n }\end{array}$ & 144 & 136 & 150 & 146 & 576 \\
\hline Age yrs & $62.7(49-78)$ & $63.3(50-79)$ & $61.9(50-78)$ & $61.8(50-77)$ & $62.4(49-79)$ \\
\hline Time since diagnosis yrs & $7.5(0-31)$ & $7.0(0-43)$ & $6.1(0-39)$ & $6.1(0-31)$ & $6.6(0-43)$ \\
\hline $\begin{array}{l}\text { Smokers: habitual/ } \\
\text { occasional/previous }\end{array}$ & 70/9/92 & $68 / 7 / 91$ & $77 / 7 / 93$ & $79 / 9 / 85$ & $294 / 32 / 361$ \\
\hline FEV $_{1} \mathrm{~L}^{\#}$ & $1.44(0.72-2.51)$ & $1.49(0.73-2.88)$ & $1.51(0.90-2.48)$ & $1.47(0.71-0.57)$ & $1.48(0.71-2.88)$ \\
\hline FEV1 \% pred & $53.1(38-70)$ & $54.4(30-73)$ & $54.7(37-71)$ & $53.8(38-70)$ & $54.0(30-73)$ \\
\hline $\mathrm{FVC} \mathrm{L}^{\#}$ & $2.59(1.05-4.36)$ & $2.68(0.98-6.08)$ & $2.64(1.41-5.53)$ & $2.60(1.11-5.53)$ & $2.63(0.98-6.08)$ \\
\hline FEV1/FVC \% pred & $74.1(41-127)$ & $74.5(41-112)$ & $76.0(40-119)$ & $75.2(42-116)$ & $75.0(40-127)$ \\
\hline Reversibility \% pred & $6.7(-35-55)$ & $5.8(-14-44)$ & $6.5(-12-92)$ & $6.7(-27-41)$ & $6.4(-35-92)$ \\
\hline BDI & $6.2(0-12)$ & $6.4(0-11)$ & $6.4(0-12)$ & $6.5(0-12)$ & $6.4(0-12)$ \\
\hline $\begin{array}{l}\text { Puffs of relief } \\
\text { medication } \cdot \text { night }^{-1}\end{array}$ & $0.54(0-3.2)$ & $0.52(0-4.4)$ & $0.63(0-6.8)$ & $0.51(0-8.4)$ & $0.55(0-8.4)$ \\
\hline $\begin{array}{l}\text { Puffs of relief } \\
\text { medication } \cdot \text { day }^{-1}\end{array}$ & $2.95(0-11.3)$ & $2.77(0-12.4)$ & $3.05(0-11.1)$ & $2.70(0-8.7)$ & $2.87(0-12.4)$ \\
\hline Total symptom score ${ }^{\#}$ & $5.94(1.9-13.6)$ & $5.30(1.2-12.3)$ & $5.71(1.4-13.2)$ & $5.55(1.0-14.2)$ & $5.63(1.0-14.2)$ \\
\hline Sleep disturbance & $1.84(1.0-4.3)$ & $1.64(1.0-3.7)$ & $1.77(1.0-4.0)$ & $1.73(1.0-4.8)$ & $1.74(1.0-4.8)$ \\
\hline Breathlessness & $2.61(1.0-5.0)$ & $2.48(1.0-4.6)$ & $2.63(1.0-4.9)$ & $2.51(1.0-4.6)$ & $2.56(1.0-5.0)$ \\
\hline Cough & $2.32(1.0-5.0)$ & $2.16(1.0-5.0)$ & $2.29(1.0-4.8)$ & $2.31(1.0-5.0)$ & $2.27(1.0-5.0)$ \\
\hline Chest tightness & $1.94(1.0-5.0)$ & $1.91(1.0-4.2)$ & $1.91(1.0-4.7)$ & $1.88(1.0-4.9)$ & $1.91(1.0-5.0)$ \\
\hline
\end{tabular}

Data are presented as mean (range). M: male; F: female; FEV1: forced expiratory volume in one second; FVC: forced vital capacity; BDI: baseline dyspnoea index. \#. geometric mean. 
Table 2. - Total and individual symptom scores after 12 weeks of treatment

\begin{tabular}{|c|c|c|c|c|c|}
\hline \multirow[t]{2}{*}{ Parameter } & \multirow[t]{2}{*}{ Treatment } & \multirow[t]{2}{*}{ Mean } & \multicolumn{3}{|c|}{ Difference relative to placebo } \\
\hline & & & $\%$ & $95 \% \mathrm{CI}$ & p-value \\
\hline \multirow[t]{4}{*}{ Sleep disturbance } & Formoterol $4.5 \mu \mathrm{g}$ & 1.64 & 99.32 & $93.39-105.62$ & 0.8271 \\
\hline & Formoterol $9 \mu \mathrm{g}$ & 1.66 & 100.60 & $94.51-107.08$ & 0.8506 \\
\hline & Formoterol $18 \mu \mathrm{g}$ & 1.56 & 94.29 & $88.71-100.22$ & 0.0588 \\
\hline & Placebo & 1.65 & & & \\
\hline \multirow{4}{*}{ Breathlessness } & Formoterol $4.5 \mu \mathrm{g}$ & 2.29 & 96.75 & $91.13-102.72$ & 0.2784 \\
\hline & Formoterol $9 \mu \mathrm{g}$ & 2.19 & 92.65 & $87.20-98.44$ & 0.0136 \\
\hline & Formoterol $18 \mu \mathrm{g}$ & 2.15 & 90.76 & $85.53-96.31$ & 0.0014 \\
\hline & Placebo & 2.37 & & & \\
\hline \multirow[t]{4}{*}{ Cough } & Formoterol $4.5 \mu \mathrm{g}$ & 2.01 & 96.64 & $90.75-102.91$ & 0.2864 \\
\hline & Formoterol $9 \mu \mathrm{g}$ & 2.03 & 97.78 & $91.73-104.23$ & 0.4905 \\
\hline & Formoterol $18 \mu \mathrm{g}$ & 2.03 & 97.57 & $91.67-103.85$ & 0.4391 \\
\hline & Placebo & 2.08 & & & \\
\hline \multirow[t]{4}{*}{ Chest tightness } & Formoterol $4.5 \mu \mathrm{g}$ & 1.81 & 96.56 & $90.59-102.93$ & 0.2822 \\
\hline & Formoterol $9 \mu \mathrm{g}$ & 1.66 & 88.98 & $83.40-94.93$ & 0.0004 \\
\hline & Formoterol $18 \mu \mathrm{g}$ & 1.72 & 91.99 & $86.35-98.01$ & 0.0099 \\
\hline & Placebo & 1.87 & & & \\
\hline \multirow[t]{4}{*}{ Total symptom score ${ }^{\#}$} & Formoterol $4.5 \mu \mathrm{g}$ & 4.68 & 94.05 & $86.23-102.58$ & 0.1660 \\
\hline & Formoterol $9 \mu \mathrm{g}$ & 4.58 & 92.16 & $84.39-100.64$ & 0.0691 \\
\hline & Formoterol $18 \mu \mathrm{g}$ & 4.34 & 87.25 & $80.06-95.09$ & 0.0019 \\
\hline & Placebo & 4.97 & & & \\
\hline
\end{tabular}

Data are presented as adjusted geometric means unless otherwise stated. CI: confidence interval. ${ }^{\#}$ : adjusted geometric means calculated from the multiplicative analysis of the average total symptom score.

in total symptom score versus the placebo group $(\mathrm{p}=0.002)$ was observed after treatment with $18 \mu \mathrm{g}$ formoterol (table 2). The decrease in symptoms obtained with the $9 \mu \mathrm{g}$ and $4.5 \mu \mathrm{g}$ doses ( 8 and $6 \%$, respectively) was not statistically significantly different from placebo.

Average scores for all four individual symptoms decreased during formoterol treatment, compared with placebo, with statistically significant improvements in breathlessness and chest tightness for both the $9 \mu \mathrm{g}$ and $18 \mu \mathrm{g}$ doses (table 2).

For the placebo group, $6.6 \%$ of treatment days were symptom free at the end of treatment. After $4.5 \mu \mathrm{g}$, $9 \mu \mathrm{g}$, and $18 \mu \mathrm{g}$ b.i.d. formoterol, an increase in symptom-free days of $21 \%, 71 \%$ and $86 \%$ respectively was observed (table 3 ). The difference compared with placebo was statistically significant for the $9 \mu \mathrm{g}$ and $18 \mu \mathrm{g}$ b.i.d. groups ( $\mathrm{p}=0.025$ and 0.006 , respectively).

Table 3. - Percentage of symptom-free days after 12 weeks of treatment

\begin{tabular}{|c|c|c|c|c|c|}
\hline \multirow[t]{2}{*}{ Parameter } & \multirow[t]{2}{*}{ Treatment } & \multirow[t]{2}{*}{ Mean } & \multicolumn{3}{|c|}{ Difference compared with placebo } \\
\hline & & & $\%$ & $95 \% \mathrm{CI}$ & $\mathrm{p}$-value \\
\hline \multirow{4}{*}{ Nights with no sleep disturbance $\%$} & Formoterol $4.5 \mu \mathrm{g}$ & 50.67 & 3.12 & $-3.12-9.37$ & 0.3267 \\
\hline & Formoterol $9 \mu \mathrm{g}$ & 48.61 & 1.06 & $-5.25-7.38$ & 0.7406 \\
\hline & Formoterol $18 \mu \mathrm{g}$ & 54.52 & 6.97 & $0.79-13.15$ & 0.0271 \\
\hline & Placebo & 47.55 & & & \\
\hline \multirow[t]{4}{*}{ Days with no breathlessness $\%$} & Formoterol $4.5 \mu \mathrm{g}$ & 17.38 & 2.51 & $-2.94-7.97$ & 0.3659 \\
\hline & Formoterol $9 \mu \mathrm{g}$ & 21.43 & 6.57 & $1.04-12.10$ & 0.0199 \\
\hline & Formoterol $18 \mu \mathrm{g}$ & 22.43 & 7.57 & $2.16-12.98$ & 0.0062 \\
\hline & Placebo & 14.86 & & & \\
\hline \multirow[t]{4}{*}{ Days with no cough \% } & Formoterol $4.5 \mu \mathrm{g}$ & 29.92 & 3.26 & $-2.48-9.00$ & 0.2651 \\
\hline & Formoterol $9 \mu \mathrm{g}$ & 30.84 & 4.18 & $-1.64-10.00$ & 0.1591 \\
\hline & Formoterol $18 \mu \mathrm{g}$ & 30.49 & 3.83 & $-1.86-9.53$ & 0.1869 \\
\hline & Placebo & 26.66 & & & \\
\hline \multirow[t]{4}{*}{ Days with no chest tightness $\%$} & Formoterol $4.5 \mu \mathrm{g}$ & 40.86 & 4.25 & $-2.02-10.53$ & 0.1838 \\
\hline & Formoterol $9 \mu \mathrm{g}$ & 48.26 & 11.65 & $5.29-18.01$ & 0.0003 \\
\hline & Formoterol $18 \mu \mathrm{g}$ & 43.86 & 7.25 & $1.02-13.48$ & 0.0225 \\
\hline & Placebo & 36.6 & & & \\
\hline \multirow[t]{4}{*}{ Symptom-free days \% } & Formoterol $4.5 \mu \mathrm{g}$ & 8.0 & 1.4 & $-2.7-5.4$ & 0.5094 \\
\hline & Formoterol $9 \mu \mathrm{g}$ & 11.3 & 4.7 & $0.6-8.8$ & 0.0249 \\
\hline & Formoterol $18 \mu \mathrm{g}$ & 12.3 & 5.7 & $1.6-9.7$ & 0.0057 \\
\hline & Placebo & 6.6 & & & \\
\hline
\end{tabular}

Data are presented as adjusted geometric means unless otherwise stated; CI: confidence interval. 


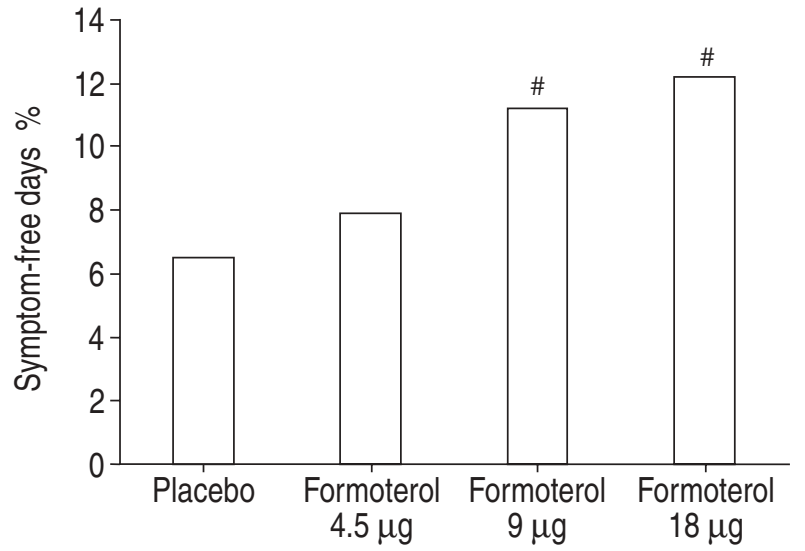

Fig. 1.-Percentage of symptom-free days after 12 week treatment with formoterol or placebo. ${ }^{\#}: \mathrm{p}<0.03$.

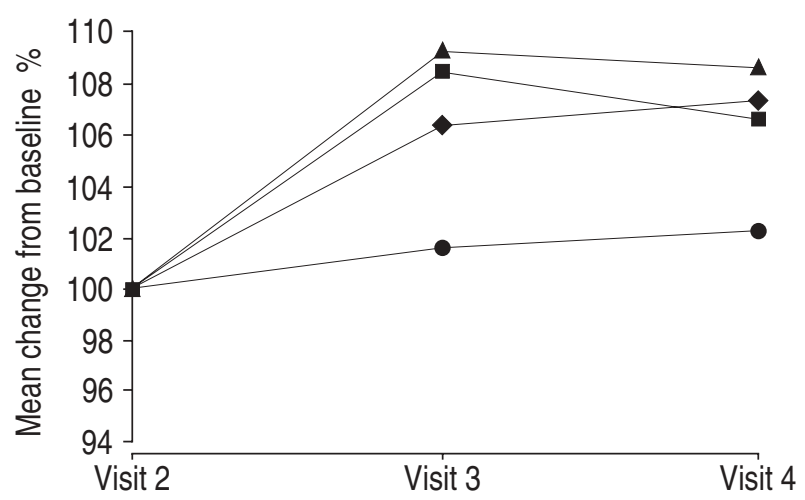

Fig. 2.-Forced expiratory volume in one second change from baseline at clinic visits compared with placebo after treatment with formoterol. $\diamond: 18 \mu \mathrm{g} ; \boldsymbol{\square}: 9 \mu \mathrm{g} ; \boldsymbol{\Delta}: 4.5 \mu \mathrm{g} ; \boldsymbol{0}$ : placebo.

A statistically significant dose-response relationship could not be demonstrated for total symptom scores, but was evident for the number of symptom-free days $(\mathrm{p}<0.05$, fig. 1$)$.

Data for individual symptoms expressed as percentage of symptom-free days are shown in table 3 . In this analysis, the decrease in night-time sleep disturbance in the $18 \mu \mathrm{g}$ formoterol group was statistically significant compared with placebo $(\mathrm{p}=0.03)$.

\section{Use of relief medication}

In all groups (including placebo), the daily use of relief medication was lower during treatment than during run-in. Formoterol $(9 \mu \mathrm{g}$ and $18 \mu \mathrm{g})$ significantly reduced the need for relief medication compared with placebo $(-18 \%$ and $-25 \%$, respectively; $\mathrm{p}=0.008$ and $\mathrm{p}<0.001)$.

\section{Spirometry}

All doses of formoterol produced statistically significant increases in FEV1 compared with placebo (fig. 2) ( $\mathrm{p}=0.010,0.039$, and 0.001 for the $4.5 \mu \mathrm{g}$, $9 \mu \mathrm{g}$, and $18 \mu \mathrm{g}$ formoterol groups, respectively). A statistically significant improvement in FVC was seen for $18 \mu \mathrm{g}$ formoterol only, relative to placebo, while no statistically significant change in FEF $25-75 \%$ was observed.

\section{Shuttle walking test}

The SWT was performed by 645 patients. The 42 patients who did not perform the test were withdrawn from the study before Visit 3 . There was considerable variation in baseline walking ability; approximately $2.5 \%$ of subjects were able to walk or run $>800 \mathrm{~m}$ but conversely, $1 \%$ were unable to walk $100 \mathrm{~m}$. The average increase in walking distance was fairly small and of the same magnitude for all groups (table 4). An increase in Borg dyspnoea score of $\sim 2.5$, an average final Borg score of $\sim 4$ (representing "somewhat severe"), and a change in pulse rate of 28-31 beats $\cdot \min ^{-1}$ was observed in all groups, including placebo at completion of the SWT.

\section{Baseline and Transitional Dyspnoea Index}

The mean BDI for the whole study population was 6.4 on a scale of $0-12$ (table 1). The mean TDI in the placebo group was 0.62 , compared with 1.29 , 1.16 , and 1.77 (on a possible scale of -9 to +9 ) in the $4.5 \mu \mathrm{g}, 9 \mu \mathrm{g}$, and $18 \mu \mathrm{g}$ formoterol groups, respectively. The TDI was statistically significant in the group treated with $18 \mu \mathrm{g}$ formoterol b.i.d. compared with the placebo group $(\mathrm{p}=0.002)$.

\section{Safety}

Patients who took, or had the opportunity to take, at least one dose of an investigational product (including placebo) were included in the safety evaluation: 690 patients (470 males, 220 females). The 10 most frequently reported adverse events, plus the expected events tremor and palpitations, are listed in table 5. There were some differences in the number of

Table 4. - Walking distance in shuttle walking test. baseline values and change from baseline

\begin{tabular}{lcccc}
\hline & Formoterol 4.5 $\mu \mathrm{g}$ & Formoterol 9 $\mu \mathrm{g}$ & Formoterol 18 $\mu \mathrm{g}$ & Placebo \\
\hline Baseline m (range) & $388.8(70-960)$ & $406.7(90-910)$ & $411.8(60-1020)$ & $410.5(100-950)$ \\
Change m (SE) & $19.58(7.83)$ & $21.55(8.26)$ & $21.08(7.85)$ & $19.58(7.99)$ \\
$95 \%$ Confidence interval & $4.21-34.95$ & $5.33-37.77$ & $5.67-36.49$ & $3.90-35.27$ \\
\hline
\end{tabular}

Data are expressed as adjusted means values unless otherwise stated. 
Table 5. - Ten most frequently reported adverse events by preferred term, plus tremor and palpitations

\begin{tabular}{lcccc}
\hline Adverse event & Formoterol $4.5 \mu \mathrm{g}$ b.i.d. & Formoterol $9 \mu \mathrm{g}$ b.i.d. & Formoterol $18 \mu \mathrm{g}$ b.i.d. & Placebo \\
\hline Subjects n & 171 & 169 & 178 & 174 \\
Deterioration of COPD & $7(4)$ & $12(7)$ & $18(10)$ & $16(9)$ \\
Respiratory infection & $21(12)$ & $24(14)$ & $17(10)$ & $18(10)$ \\
Chest pain & $1(1)$ & $2(1)$ & $5(3)$ & $2(1)$ \\
Back pain & $1(1)$ & $4(2)$ & $4(2)$ & $3(2)$ \\
Headache & $4(2)$ & $3(2)$ & $4(2)$ & $8(5)$ \\
Hyperglycaemia & & $2(1)$ & $3(2)$ & $3(2)$ \\
Hypertension & $9(5)$ & $1(1)$ & $3(2)$ & $2(1)$ \\
Pain & $3(2)$ & $5(3)$ & $3(2)$ & $4(2)$ \\
Pharyngitis & $1(1)$ & $5(3)$ & $3(2)$ & $3(2)$ \\
Tachycardia & $1(1)$ & $1(1)$ & & $1(1)$ \\
Tremor & & & \\
Palpitations & & & & \\
\hline
\end{tabular}

Data are presented as $\mathrm{n}$ of adverse events with \% of patients reporting in parentheses. COPD: chronic obstructive pulmonary disease.

adverse events between the treatments but these were not considered to signal any particularly negative or unknown effect of formoterol. Of the well known class effects of $\beta_{2}$-agonists, tachycardia and tremor, only the latter showed a relation to formoterol treatment.

Twenty-eight serious adverse events were reported, three in the placebo group and 25 in the three formoterol groups. There were no significant differences between the groups treated with formoterol in terms of the number, type or intensity of events. One event, tachycardia in connection with a COPD exacerbation in the $9 \mu \mathrm{g}$ formoterol group, was considered to have a possible causal relationship with the drug by the investigator. Nine patients were withdrawn from the study because of serious adverse events: these included three patients from the $4.5 \mu \mathrm{g}$ formoterol group (bronchospasm, transient blindness and neuralgia); three patients from the $9 \mu \mathrm{g}$ formoterol group (pulmonary embolism, rectal carcinoma, atrial fibrillation); two patients from the $18 \mu \mathrm{g}$ formoterol group (cardiomyopathy, fracture); and one patient from the placebo group (cerebrovascular disorder).

There were 114 withdrawals from the study during treatment; of these 42 were due to COPD deterioration, 18 due to other adverse events and 54 due to other reasons. The overall withdrawal frequency was similar between the four groups (ranging between 16 and $19 \%$ ) and a log-rank test revealed no significant difference between the groups with respect to their survival distributions. Deterioration of COPD and respiratory infection were the two most commonly reported adverse events in all treatment groups.

\section{Discussion}

In the present study, the use of the long-acting $\beta_{2}$-agonist formoterol as maintenance treatment in patients with moderate to severe COPD was associated with improved symptom control compared with placebo. In addition, an improvement in FEV1 was observed with all doses of formoterol, compared with placebo.
There are differences in the definition of airway obstruction in different COPD guidelines. According to the ERS document [1], obstruction is present when the $\mathrm{FEV} / \mathrm{FVC}$ is $<88 \%$ pred in males and $<89 \%$ pred in females, in keeping with the inclusion criteria in the present study. The American Thoracic Society guidelines [3] do not define such limits. Lack of reversibility is also an important part of the definition, and it is apparent that some patients were included in this study that either showed reversibility $(>10 \%$ pred in $23 \%$ of the patients) or a better FEV1/ FVC ratio than required in the inclusion criteria $(9 \%$ of patients). Statistical analysis confirmed, however, that inclusion or exclusion of these patients in the analyses had no significant influence on the results.

The evidence regarding the effect of short-acting $\beta_{2}$-agonists in COPD patients is contradictory, some studies showed improved lung function variables, exercise capacity and symptom scores [5, 6], and others reported no significant improvement in lung function or exercise capacity $[13,14]$. The improvement in mean FEV1 and FVC compared with placebo seen at all doses in the present study (statistically significant for all formoterol doses with FEV1 and for $18 \mu \mathrm{g}$ formoterol with FVC) demonstrate the reversible element of bronchoconstriction in COPD; in the treatment of this, formoterol has the added benefit over short-acting $\beta_{2}$-agonists of a long duration of effect. A significant effect on other parameters, such as symptoms of breathlessness and chest tightness, use of relief medication and symptom-free days, was obtained at a dose of at least $9 \mu \mathrm{g}$ b.i.d., with a dose-dependent relationship evident for the percentage of symptom-free days. The significant reduction in total symptom scores and improvement in nights without awakenings with the highest dose indicates that added benefits may be obtained by increasing the dose of formoterol from $9 \mu \mathrm{g}$ to $18 \mu \mathrm{g}$ b.i.d.

The SWT has been used before in the assessment of patients in pulmonary rehabilitation programmes [15]. Several factors may have contributed to the failure to detect a difference between the treatment and placebo groups, using this test, in the present study. Firstly, there was a large variation in walking ability (range 
$60-1,020 \mathrm{~m}$ within the study population), and the progressive nature of the test would have allowed little room for relatively fit patients to improve. In addition, a relatively low Borg dyspnoea score, approximately 4 (representing somewhat severe dyspnoea), was reached when the SWT was stopped, suggesting that maximal performance level had not been achieved, perhaps because giving encouragement was not allowed. In another study of COPD patients, in which both a bicycle ergometer test and the SWT were used, the Borg score reached with the former was twice as high as with the latter [16]. Thus, it seems that this test was not the most appropriate for this group of patients. The endurance SWT [17], in which exercise capacity is measured at a constant, individually set, submaximal load, may be more suitable in this situation.

Studies have been performed on the effects of another long-acting $\beta_{2}$-agonist, salmeterol, on exercise capacity in COPD patients. Grove et al. [18] found a small symptomatic effect, evidenced as a decrease in perceived exertion in the six-min walk, while a later study revealed a decrease in breathlessness after walking [19]. In the former study, the possibility was raised that salmeterol might relieve expiratory obstruction, decreasing gas trapping and allowing breathing to occur at a lower residual volume, but there was no clear evidence of any alteration in the level of gas trapping. The second study did not specifically investigate gas trapping but also suggested that it might be involved in the observed improvement.

Gas trapping, a result of the increased expiratory airflow resistance characteristic of COPD, leads to hyperinflation, and this may result in a small FEV1 response and thus underestimation of the beneficial effect of bronchodilators in severe COPD [20]. During exercise, dynamic hyperinflation will decrease the inspiratory capacity, which is low even at rest. BELMAN et al. [21] demonstrated a reduction in this hyperinflation with albuterol. The improvement seen in breathlessness and chest tightness in the present study, in spite of a fairly small increase in FEV1, may possibly be explained by a reduction in hyperinflation, although TAUBE et al. [22] consider that such improvements correlate well with changes in forced inspiratory volume. MAESEN et al. [23] looked at the work of breathing and airway resistance at rest, rather than focusing on forced expiration tests, and found significant improvements up to $12 \mathrm{~h}$ after a single inhalation of formoterol, in spite of poor reversibility in FEV1.

Except for the well-known $\beta_{2}$-agonist class effect symptom of tremor, there was no obvious causal relationship between undesirable effects and treatment with formoterol. The results of this study thus show that formoterol is well tolerated and safe in COPD patients.

The present results are confirmed in a recently published study, in which formoterol was inhaled at doses of 12 and $24 \mu \mathrm{g}$ b.i.d. via another inhaler in patients with COPD [24]. When given in these doses formoterol improved lung function, symptoms and quality of life, both in COPD patients with and without reversibility to $\beta_{2}$-agonists, and performed better than inhaled ipratropium bromide.

In conclusion, the present study confirmed the effectiveness of maintenance treatment with the long-acting $\beta_{2}$-agonist formoterol, inhaled via Turbuhaler $\mathbb{R}$, in chronic obstructive pulmonary disease. Formoterol $(9 \mu \mathrm{g}$ and $18 \mu \mathrm{g}$ b.i.d.) significantly reduced breathlessness and chest tightness, and the number of symptom-free days increased in a dose-dependent manner. A significant improvement in forced expiratory volume in one second was seen at all doses tested. Although no effect on exercise capacity could be demonstrated, the results of the study are in agreement with those of others where relief of symptoms and bronchial obstruction have been demonstrated, even in patients with limited reversibility to $\beta_{2}$-agonists.

\footnotetext{
Acknowledgements. List of investigators: Australia: P.J. Thompson, C. Jenkins, R. Scicchitano, C. Mitchell, D. Lindsay, P.A. Frith, M. Bint, L. Irving, A.R. Rubinfeld; Belgium: J. Machiels, A. van Meerhaeghe, P. Bartsch, P. Ortmanns, A. Leloup; Denmark: L.C. Laursen, E.P. Munch, R. Dahl, J. Korsgaard Jensen, H. Harving; Germany: J. Adler, B. Bartuschka, H. Blum, W. Böhning, E. Bölsckei, T. Drescher, G. Dunkhase, R. Gebhardt, D. Hahn, H. Matthys, H. Querfurt, K. Schussmann, H. Weber, K. Günsberg; Hungary: A. Devai, M. Bisits, K. Puha, E. Radeczky, G. Kelen, E. Prugberger; The Netherlands: J. de Munck, A.J.M. Schreurs, J. Creemers, J.H. Strijbos, J. van Noord; Norway: K. Skaug, E. Glöersen, J. Asmervik; Poland: W. Terlecka, A. Rojek, T. Wilewska-Klubo, J. Milanowski, A. Szczeklik, K. Krawczyk, J. Kozielski, M. Szmidt, E. Chyczewska, J. Hanzlik, J. Bielak, W. Pierzchala, E. Rogala, T. Plusa, R. Matusiewicz, W. Szafranski, M. Stopinski, S. Niemczyk, P. Nalepa; UK: G.J. Gibson, G. Basran, G. Crompton, W. Mac Nee, L.M. Campbell, C. Corrigan, S. Langley, M. Duckworth, N.A. Gough, K. Gruffydd-Jones, S. Rowlands.
}

\section{References}

1. Siafakas NM, Vermeire P, Pride NB, et al. Optimal assessment and management of chronic obstructive pulmonary disease (COPD). The European Respiratory Society Task Force. Eur Respir J 1995; 8: 13981420.

2. Hurd S. The impact of COPD on lung health worldwide: epidemiology and incidence. Chest 2000; 117: S1-S4.

3. Standards for the diagnosis and care of patients with chronic obstructive pulmonary disease. American Thoracic Society. Am J Respir Crit Care Med 1995; 152: S77-S121.

4. BTS guidelines for the management of chronic obstructive pulmonary disease. The COPD Guidelines Group of the Standards of Care Committee of the BTS. Thorax 1997; 52: S1-S28.

5. Guyatt GH, Townsend M, Pugsley SO, et al. Bronchodilators in chronic air-flow limitation. Effects on 
airway function, exercise capacity, and quality of life. Am Rev Respir Dis 1987; 135: 1069-1074.

6. Lipworth BJ, Clark RA, Dhillon DP, McDevitt DG. Comparison of the effects of prolonged treatment with low and high doses of inhaled terbutaline on betaadrenoceptor responsiveness in patients with chronic obstructive pulmonary disease. Am Rev Respir Dis 1990; 142: 338-342.

7. Bartow RA, Brogden RN. Formoterol. An update of its pharmacological properties and therapeutic efficacy in the management of asthma. Drugs 1998; 55: 303-322.

8. Petty TL. The National Mucolytic Study. Results of a randomized, double-blind, placebo-controlled study of iodinated glycerol in chronic obstructive bronchitis. Chest 1990; 97: 75-83.

9. Quanjer PH, Tammeling GJ, Cotes JE, et al. Lung volumes and forced ventilatory flows. Report Working Party Standardization of Lung Function Tests, European Community for Steel and Coal. Official Statement of the European Respiratory Society. Eur Respir J 1993; 16: S5-40.

10. Singh SJ, Morgan MD, Scott S, Walters D, Hardman AE. Development of a shuttle walking test of disability in patients with chronic airways obstruction. Thorax 1992; 47: 1019-1024.

11. Borg GA. Psychophysical bases of perceived exertion. Med Sci Sports Exerc 1982; 14: 377-381.

12. Mahler DA, Weinberg DH, Wells CK, Feinstein AR. The measurement of dyspnea. Contents, interobserver agreement, and physiologic correlates of two new clinical indexes. Chest 1984; 85: 751-758.

13. Taylor DR, Buick B, Kinney C, Lowry RC, McDevitt DG. The efficacy of orally administered theophylline, inhaled salbutamol, and a combination of the two as chronic therapy in the management of chronic bronchitis with reversible air-flow obstruction. $\mathrm{Am}$ Rev Respir Dis 1985; 131: 747-751.

14. Evald T, Keittelmann S, Sindrup JH, Lange P. The effect of inhaled terbutaline on FEV1, FVC, dyspnoea and walking distance in patients with chronic obstructive lung disease. Respir Med 1992; 86: 93-96.
15. Singh SJ, Smith DL, Hyland ME, Morgan MD. A short outpatient pulmonary rehabilitation programme: immediate and longer-term effects on exercise performance and quality of life. Respir Med 1998; 92: 11461154.

16. Gray-Donald K, Gibbons L, Shapiro SH, Martin JG. Effect of nutritional status on exercise performance in patients with chronic obstructive pulmonary disease. Am Rev Respir Dis 1989; 140: 1544-1548.

17. Revill SM, Morgan MD, Singh SJ, Williams J, Hardman AE. The endurance shuttle walk: a new field test for the assessment of endurance capacity in chronic obstructive pulmonary disease. Thorax 1999; 54: 213-222.

18. Grove A, Lipworth BJ, Reid P, et al. Effects of regular salmeterol on lung function and exercise capacity in patients with chronic obstructive airways disease. Thorax 1996; 51: 689-693.

19. Boyd G, Morice AH, Pounsford JC, Siebert M, Pelis $\mathrm{N}$, Crawford C. An evaluation of salmeterol in the treatment of chronic obstructive pulmonary disease (COPD). Eur Respir J 1997; 10: 815-821.

20. O'Donnell DE. Assessment of bronchodilator efficacy in symptomatic COPD: Is spirometry useful? Chest 2000; 117: S42-S47.

21. Belman MJ, Botnick WC, Shin JW. Inhaled bronchodilators reduce dynamic hyperinflation during exercise in patients with chronic obstructive pulmonary disease. Am J Respir Crit Care Med 1996; 153: 967975.

22. Taube C, Lehnigk B, Paasch K, Kirsten DK, Jörres RA, Magnussen H. Factor analysis of changes in dyspnea and lung function parameters after bronchodilation in Chronic Obstructive Pulmonary Disease. Am J Respir Crit Care Med 2000; 162: 216-220.

23. Maesen BL, Westermann CJ, Duurkens VA, van den Bosch JM. Effects of formoterol in apparently poorly reversible chronic obstructive pulmonary disease. Eur Respir J 1999; 13: 1103-1108.

24. Dahl R, Greefhorst LAPM, Nowak D, et al. Inhaled formoterol dry powder versus ipratropium bromide in chronic obstructive pulmonary disease. Am J Respir Crit Care Med 2001; 164: 778-784. 